\title{
Surface expression of protein A on magnetosomes and capture of pathogenic bacteria by magnetosome/antibody complexes
}

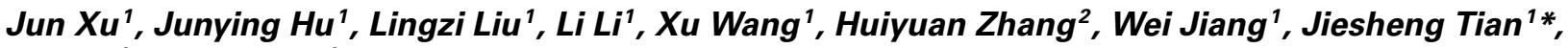 \\ Ying $L i^{1}$ and Jilun $L i^{1}$
}

${ }^{1}$ Department of Microbiology, College of Biological Sciences, China Agricultural University, Beijing, China

${ }^{2}$ Food Safety Testing Centre, Beijing Entry-Exit Inspection and Quarantine Bureau, Beijing, China

\section{Edited by:}

Wei Lin, Chinese academy of Sciences, China

Reviewed by:

Raz Zarivach, Ben Gurion University of the Negev, Israel

Changqian Cao, Chinese Academy

of Sciences, China

*Correspondence:

Jiesheng Tian, Department of

Microbiology, College of Biological Sciences, China Agricultural

University, Room 3037, Yuan Ming

Yuan West Road No. 2, Haidian

District, Beijing 100193, China

e-mail: tianhome@cau.edu.cn
Magnetosomes are membrane-enclosed magnetite nanocrystals synthesized by magnetotactic bacteria (MTB). They display chemical purity, narrow size ranges, and species-specific crystal morphologies. Specific transmembrane proteins are sorted to the magnetosome membrane (MM). MamC is the most abundant MM protein of Magnetospirillum gryphiswaldense strain MSR-1. MamF is the second most abundant MM protein of MSR-1 and forms stable oligomers. We expressed staphylococcal protein A (SPA), an immunoglobulin-binding protein from the cell wall of Staphylococcus aureus, on MSR-1 magnetosomes by fusion with MamC or MamF. The resulting recombinant magnetosomes were capable of self-assembly with the Fc region of mammalian antibodies (Abs) and were therefore useful for functionalization of magnetosomes. Recombinant plasmids pBBR-mamC-spa and pBBR-mamF-spa were constructed by fusing spa (the gene that encodes SPA) with mamC and mamF, respectively. Recombinant magnetosomes with surface expression of SPA were generated by introduction of these fusion genes into wild-type MSR-1 or a mamF mutant strain. Studies with a Zeta Potential Analyzer showed that the recombinant magnetosomes had hydrated radii significantly smaller than those of WT magnetosomes and zeta potentials less than $-30 \mathrm{mV}$, indicating that the magnetosome colloids were relatively stable. Observed conjugation efficiencies were as high as $71.24 \mu \mathrm{g} \mathrm{Ab}$ permg recombinant magnetosomes, and the conjugated Abs retained most of their activity. Numbers of Vibrio parahaemolyticus (a common pathogenic bacterium in seafood) captured by recombinant magnetosome/Ab complexes were measured by real-time fluorescence-based quantitative PCR. One mg of complex was capable of capturing as many as $1.74 \times 10^{7}$ Vibrio cells. The surface expression system described here will be useful for design of functionalized magnetosomes from MSR-1 and other MTB.

\footnotetext{
Keywords: Magnetospirillum gryphiswaldense, magnetosome, MamF, surface display, protein A functionalization, Vibrio parahaemolyticus
}

\section{INTRODUCTION}

The bacterium Vibrio parahaemolyticus is a major cause of foodborne illnesses resulting from consumption of raw seafood and is involved in gastroenteritis, wound infection, and septicemia (Newton et al., 2012). Conventional methods for the detection of $V$. parahaemolyticus include the use of selective, differential agar media, biochemical testing, and examination of colony morphology (Kaysner and DePaola, 2004). Such methods usually involve time-consuming laboratory procedures and provide limited knowledge regarding pathogenicity.

Techniques based on polymerase chain reaction (PCR) have been used increasingly in recent years to detect pathogenic strains of $V$. parahaemolyticus by targeting the amplification of specific gene sequences with appropriate primers. A thermolabile direct hemolysin (TLH) is specific for V.parahaemolyticus. Its gene, th, is a frequently used target in various detection strategies (Su and
Liu, 2007). However, PCR in this case is inhibited by a variety of substances present in food or in the environment (Rossen et al., 1992; Powell et al., 1994; Waleed and Peter, 2000). Removal of such inhibitory substances is a crucial step in the preparation of template DNA samples for PCR-based detection of food pathogens.

Immunomagnetic separation (IMS) is a powerful technique for the specific isolation and concentration of target bacteria from food samples (Spanová et al., 2003; Ångela et al., 2008; Mercanoglu et al., 2009). Magnetosomes (also termed bacterial magnetic particles, or BMPs; this abbreviation is used hereafter for convenience) are being used increasingly as carriers for IMS assays (Arakaki et al., 2008; Faivre and Schüler, 2008). BMPs are synthesized by MTB and are composed of membrane-enclosed, single-domain ferrimagnetic iron oxide (magnetite, $\mathrm{Fe}_{3} \mathrm{O}_{4}$ ), or iron sulfide (greigite, $\mathrm{Fe}_{3} \mathrm{~S}_{4}$ ) crystals (Schüler, 2002). At least 20 
proteins have been identified on the magnetosome membrane (MM) of Magnetospirillum gryphiswaldense strain MSR-1 (hereafter termed "MSR-1"). Grünberg et al. (2004) reported that MamC was the most abundant MM-associated protein and that MamF was the second most abundant and the most stable. Expression of foreign functional proteins on the BMP surface can be facilitated by genetic engineering of MM-associated proteins. Many recent studies have attempted to produce various types of functionalized BMPs, for instance by the BMP-specific display of functional moieties, such as enzymes, coupling groups, gold particles, or oligonucleotides (BMP surface display system, Yoshino et al., 2010).

In the present study, staphylococcal protein A (SPA) was expressed on magnetosomes by fusion with MamC or MamF. SPA is an immunoglobulin G-binding protein (antibody-binding protein) encoded by the spa gene and can be isolated from the cell wall of Staphylococcus aureus. It binds the heavy chain within the fragment crystallizable region (Fc region, or tail region) of most immunoglobulins under a wide variety of conditions (Sidorin and Solov'eva, 2011). The resulting recombinant magnetosomes (BMP-A) were capable of self-assembly with many mammalian antibodies (Abs) without a loss of Ab activity. These recombinant BMPs were characterized and their Ab-binding efficiencies were evaluated. The capture efficiencies of magnetosome complexes (BMP-A-Ab) for V. parahaemolyticus were also investigated.

\section{MATERIALS AND METHODS \\ BACTERIAL STRAINS, PRIMERS, PROBES, CULTURE MEDIA, AND GROWTH CONDITIONS}

The bacterial strains, mutants, plasmids, and primers used in this study are listed in Tables 1, 2. Escherichia coli (E. coli) strains were grown at $37^{\circ} \mathrm{C}$ in Luria-Bertani (LB) medium (Sambrook and Russel, 2001). M. gryphiswaldense strains were grown at $30^{\circ} \mathrm{C}$ in sodium lactate/ ammonium chloride/yeast extract (L AY) medium as described previously (Liu et al., 2008). Heat-killed cells of V. parahaemolyticus strain 09vp109 were from the Beijing Entry-Exit Inspection and Quarantine Bureau (Beijing, China).

Bicinchoninic acid (BCA) kits were from Pierce Biotechnology (Rockford, Illinois, USA). Abs were prepared by Kirkegaard and Perry Laboratories (KPL) Biotechnology (Gaithersburg, Maryland, USA). Other chemical reagents were from Beijing Chemical Reagents Co., China.

Primers and probes were designed using ABI 7000 Primer Express software (http://www.lifetechnologies.com/global/ en/home/technical-resources/software-downloads/abi-prism-700 0 -sequence-detection-system.html). The probe used for realtime fluorescence quantitative PCR (FQ-PCR) was labeled with 6 -carboxyfluorescein reporter dye (FAM) at the $5^{\prime}$-end and 6-carboxy-tetramethylrhodamine quencher dye (TAMRA) at the $3^{\prime}$-end.

\section{CONSTRUCTION OF RECOMBINANT PLASMIDS AND STRAINS}

Mutant strain $M$. gryphiswaldense $\triangle \mathrm{F}$ was constructed by replacing $m a m F$ with the gentamicin resistance gene (aminoglycoside acetyltransferase gene, aac). Plasmid pUC-GM was digested by $K p n I$ to generate an aac gene fragment. The upstream and downstream fragments of mamF gene were amplified by the corresponding primers (Table 2) from genomic DNA of MSR-1, and referred to as $U$ and $D$, respectively. Fragments $U$ and $D$ were digested by XbaI/KpnI and KpnI/PstI and then connected with the aac gene fragment by T4 DNA ligase to generate a U-aac-D fragment. The U-aac-D fragment was cloned into a suicide plasmid pUX19. The recombinant plasmid was transformed into E. coli S17-1 and then transferred into MSR-1 by biparental conjugation. Mutant bacterial strains were screened as described previously (Liu et al., 2008).

Table 1 | M. gryphiswaldense strains and plasmids in this study.

\begin{tabular}{|c|c|c|c|}
\hline & Strain or plasmid & Genotype & Source \\
\hline \multirow[t]{6}{*}{ Strains } & M. gryphiswaldense MSR-1 & Wild-type (WT) & DSMZ \\
\hline & M. gryphiswaldense $\Delta \mathrm{F}$ & MSR-1 mamF mutant & Present study \\
\hline & M. gryphiswaldense MSR-FA & MSR-1 harboring pBBR-mamF-spa; $\mathrm{Nx}^{r}, \mathrm{Km}^{\mathrm{r}}$ & Present study \\
\hline & M. gryphiswaldense $\Delta \mathrm{F}-\mathrm{FA}$ & mamF mutant harboring pBBR-mamF-spa; $\mathrm{Nx}^{r}, \mathrm{Km}^{r}, \mathrm{Gm}^{r}$ & Present study \\
\hline & E. coli S17-1 & $\begin{array}{l}\text { Pro thi hsdR recA, chromosomal integration of } \\
\text { RP4-2-Tc::Mu-Km::Tn7, } \mathrm{Sm}^{r} \mathrm{Tra}^{+}\end{array}$ & \\
\hline & V. parahaemolyticus 09vp109 & WT & \\
\hline \multirow[t]{3}{*}{ Plasmids } & pUC-GM & $A m p^{r}, p U C 18$ harboring gentamicin resistance gene & Laboratory collection \\
\hline & pBBR-mamC-spa & pBBR1MCS-2 harboring gene fragment of mamC-spa; $\mathrm{Km}^{r}$ & Present study \\
\hline & pBBR-mamF-spa & pBBR1MCS-2 harboring gene fragment of mamF-spa; Kmr & Present study \\
\hline
\end{tabular}

DSMZ, German Collection of Microorganisms and Cell Cultures GmbH; CGMCC, China General Microbiological Culture Collection Center. 
Table 2 | Primers used for PCR.

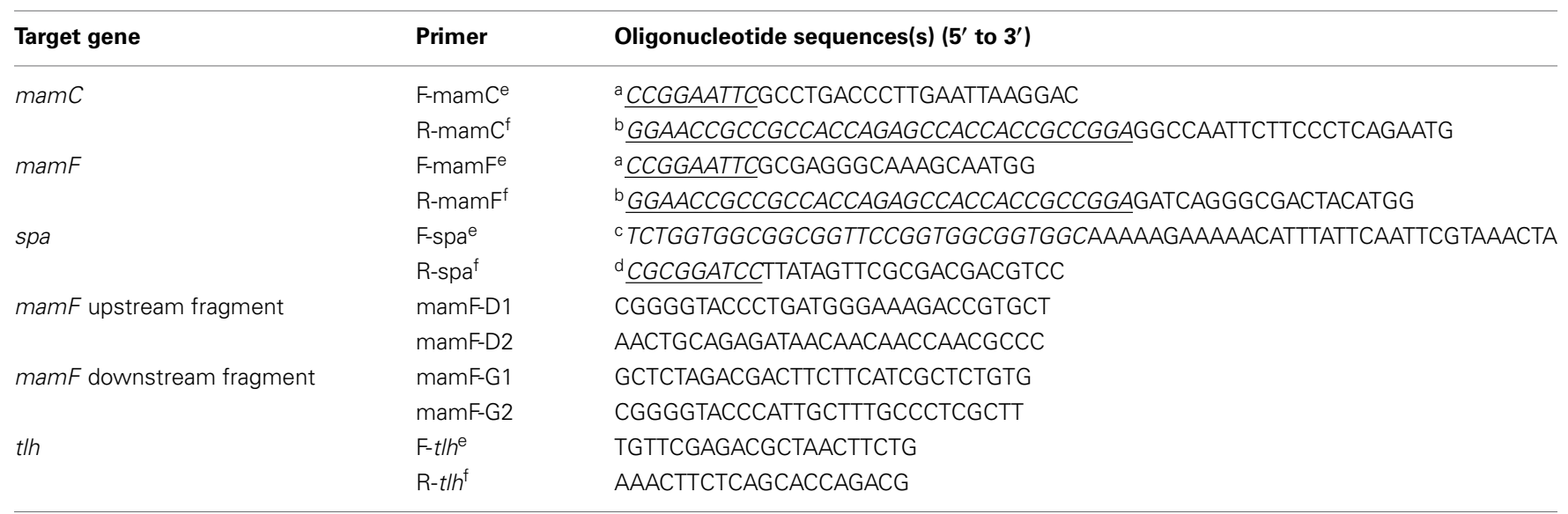

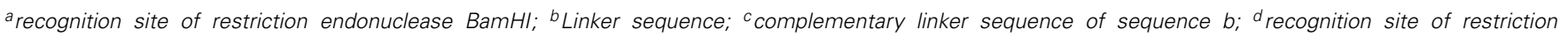
endonuclease EcoRI; ${ }^{e}$ forward primer; ${ }^{f}$ reverse primer.

mam $C, m a m F$, and spa genes were amplified from genomic DNA of MSR-1 or S. aureus ATCC 6538 by the corresponding primers (Table 2). The start codon of spa and the stop codons of $m a m C$ and $m a m F$ were removed during amplification. The three above fragments were recovered to generate mamC-spa and mamF-spa fragments by fusion PCR (Komeili et al., 2004). These two fragments were respectively cloned into pMD18-T simple cloning vector and transformed into E. coli DH5 $\alpha$. After overnight culture of the recombinant strains, two plasmids were extracted and digested with EcoRI and BamHI. The recovered fragments were then cloned into the broad host plasmid vector pBBR1MCS-2, resulting in plasmids pBBR-mamC-spa and pBBR-mamF-spa, respectively (Figure 1). These plasmids contained a linker consisting of 15 amino acids between the spa and mam genes, and recognition sites of restriction endonucleases BamHI and EcoRI flanking the sides of the mam-spa fusion genes.

Plasmids pBBR-mamC-spa and pBBR-mamF-spa were introduced into E. coli S17-1 by transformation (Sambrook and Russel, 2001) and then transferred into MSR-1 or M. gryphiswaldense $\Delta \mathrm{F}$ by conjugation as described previously (Liu et al., 2008).

\section{PREPARATION OF MAGNETOSOME-AB COMPLEXES}

Magnetosomes or recombinant magnetosomes (BMP-As) of $M$. gryphiswaldense strains were isolated and purified as described previously (Li et al., 2010). The membrane proteins of BMPs or BMP-As were extracted as described by Grünberg et al. (2004) and identified by Northern blotting. The proteins of each sample (generally from $0.25 \mathrm{mg}$ magnetosomes) were separated by SDS-PAGE, and the bands were transferred onto a nitrocellulose membrane by electroblotting and blocked overnight at $4^{\circ} \mathrm{C}$. A dilute solution of primary $\mathrm{Ab}$ (mouse mAb, 0.5-5.0 mg/mL) was incubated with the membrane under gentle agitation for $1 \mathrm{~h}$ at room temperature. The membrane was rinsed to remove unbound primary $\mathrm{Ab}$ and then placed in a solution of secondary $\mathrm{Ab}$ (goat anti-mouse IgG) for $1 \mathrm{~h}$. The secondary Ab was linked to alkaline phosphatase, which was then used to catalyze 5-bromo4-chloro-3-indolyl phosphate (BCIP) and nitro blue tetrazolium
(NBT) into a blue precipitate in proportion to the amount of protein.

The hydrated radii and zeta potentials of magnetosomes were analyzed by a Zeta Potential Analyzer (Brookhaven Instruments Corp., Long Island, State of New York USA). Samples were prepared as described by Takahashi et al. (2010).

Chemical modification of magnetosomes by bis(sulfosuccinimidyl) suberate $\left(\mathrm{BS}^{3}\right)$ was performed as described previously ( $\mathrm{Li}$ et al., 2010). The procedure for self-assembly of recombinant magnetosome was as follows. BMP-A or Ab (each $1 \mathrm{mg}$ ) was resuspended in $1 \mathrm{~mL}$ of $1 \mathrm{mM}$ phosphate-buffered saline (PBS; $\mathrm{pH}$ 7.4). The magnetosome and $\mathrm{Ab}$ suspensions were mixed, placed in a mild ultrasonic bath $(30 \mathrm{~W})$ for $2 \mathrm{~min}$, and incubated on a rotary shaker at $150 \times \mathrm{g}$ for 60-90 min. The resulting BMP-A-Ab complexes were isolated by a NdFeB magnet, washed three times with $1 \mathrm{~mL}$ of $10 \mathrm{mM}$ PBS ( $\mathrm{pH} 7.4$ ), and resuspended in $500 \mu \mathrm{L}$ of $1 \mathrm{mg} / \mathrm{mL}$ Ab solution. After repeated dispersion, incubation, collection, and washing as above, the complexes were blocked with sterile $0.5 \%$ BSA solution overnight at $4^{\circ} \mathrm{C}$ and stored.

$\mathrm{Ab}$ concentrations before and after reaction with magnetosomes were determined using a BCA kit, and linkage rates were calculated by the equation:

Linkage rate $(\mu \mathrm{g} \mathrm{Ab} / \mathrm{mg}$ magnetosomes $)=(\mathrm{C} 1-\mathrm{C} 2) \times \mathrm{V} / \mathrm{M}$

where $\mathrm{C} 1=\mathrm{Ab}$ concentration before reaction with magnetosomes; $\mathrm{C} 2=\mathrm{Ab}$ concentration after reaction with magnetosomes; $\mathrm{V}=$ volume of $\mathrm{Ab}$ solution reacting with magnetosomes; $\mathrm{M}=$ weight of magnetosomes conjugated with $\mathrm{Ab}$. C1 and $\mathrm{C} 2$ were calculated by the equation $\gamma=\mathrm{kx}$, where $\gamma=\mathrm{OD}_{562}$ detected by the BCA kit; $\mathrm{x}=\mathrm{Ab}$ concentration; $\mathrm{k}=$ slope.

\section{IMS AND CAPTURE EFFICIENCY DETECTION OF V.PARAHAEMOLYTICUS BY FO-PCR}

Serially 10 -fold diluted Vibrio suspensions $\left(10^{-3}, 10^{-4}, 10^{-5}\right.$, $10^{-6}$; each $1 \mathrm{~mL}$ ) were mixed with $1 \mathrm{mg}$ BMP-A-Ab complexes. The mixtures were dispersed by sonication for $2 \mathrm{~min}$ and incubated on a rotary shaker $(150 \times \mathrm{g})$ for $1 \mathrm{~h}$ at room temperature. BMP-A-Ab-Vibrio complexes were isolated using a magnet and 


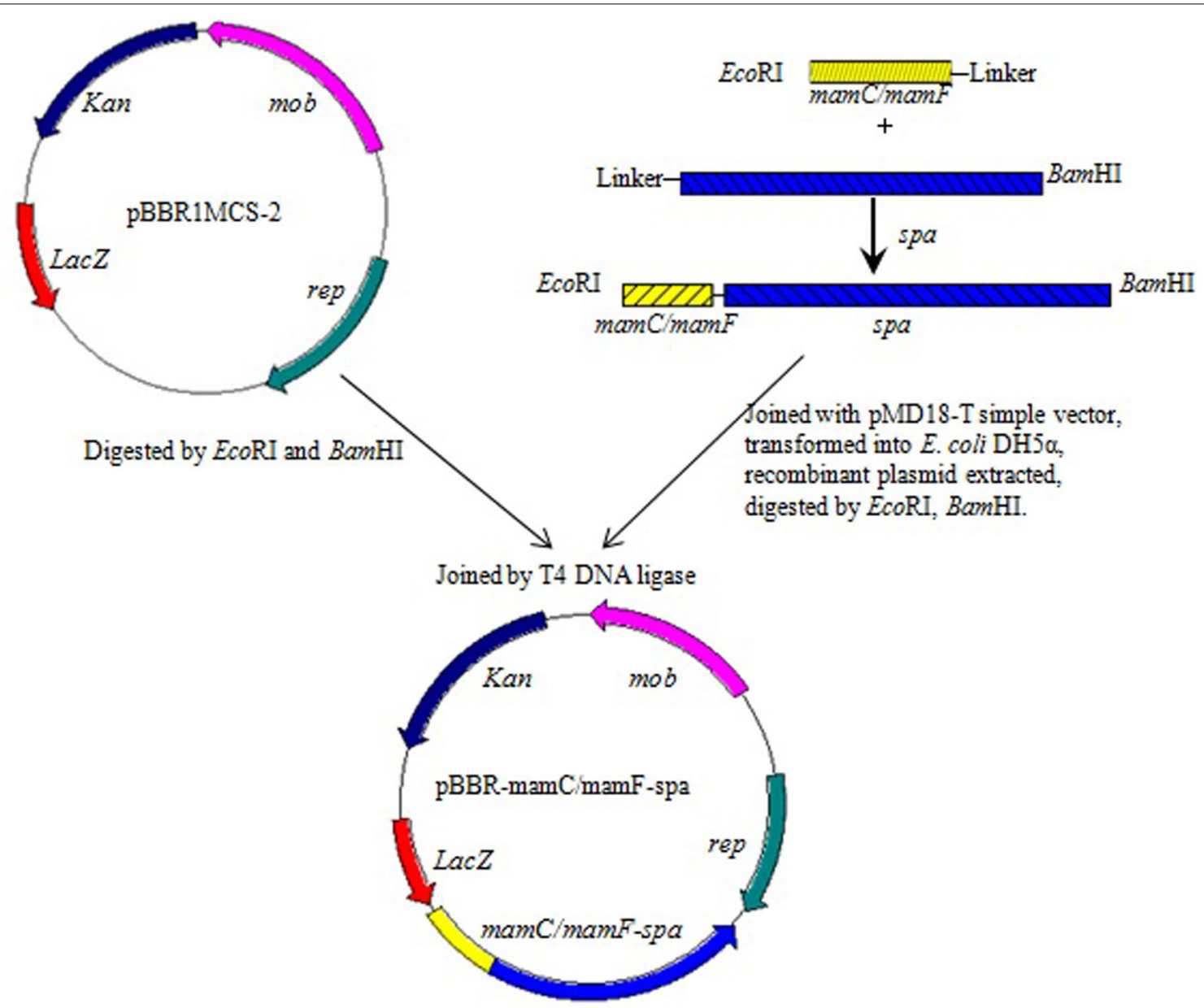

FIGURE 1 | Construction of plasmids pBBR-mamC-spa and pBBR-mamF-spa.

washed three times with $1 \mathrm{~mL}$ of $10 \mathrm{mM}$ PBS buffer to remove free bacterial cells. Control mixtures of Vibrio and BMP-As (without $\mathrm{Ab}$ ) were incubated in PBS under the same conditions. The resulting precipitate was resuspended in $100 \mu \mathrm{L}$ PBS. The concentrated cell suspension was incubated for $10 \mathrm{~min}$ at $98^{\circ} \mathrm{C}$ and centrifuged at $10,000 \times \mathrm{g}$ for $3 \mathrm{~min}$ at room temperature. The supernatants were used as templates. FQ-PCR was performed as described previously (Li et al., 2010).

$V$. parahaemolyticus strains produce species-specific TLHs, and the th gene has been used as a probe to confirm the identity of Vibrio species (McCarthy et al., 1999). We measured the fluorescence intensity of th FQ-PCR products to estimate the number of Vibrio cells trapped by BMP-A-Ab complexes. Standard curves were constructed using a $10^{-1}-10^{-6}$ serial 10 -fold dilution of Vibrio genomic DNA, and the threshold cycle $(\mathrm{Ct})$ value was plotted against the log of DNA weight (ng) by linear regression. The average weight of a pair of DNA bases is $1 \times 10^{-21} \mathrm{~g}$, and the whole genome of $V$. parahaemolyticus (5165770 bp; Makino et al., 2003) was estimated to weigh $5.2 \times 10^{-15} \mathrm{~g}$. The number of Vibrio was calculated as the amount of DNA divided by the weight of genome.

\section{RESULTS CONSTRUCTION OF RECOMBINANT PLASMIDS AND STRAINS ENCODING FUSION PROTEINS}

SPA is an immunoglobulin G-binding protein. Magnetosomespecific expression of SPA could facilitate efficient localization and appropriate orientation of various $\mathrm{Abs}$ on the surface of magnetosomes. In the present study, SPA was expressed on magnetosomes by fusing its gene (spa; $1503 \mathrm{bp}$ ) with the abundant $\mathrm{MM}$ protein genes mamC (378 bp) or mamF (336bp) from M. gryphiswaldense. The fusion genes mamC-spa and mamF-spa were generated by fusion PCR from mamC, mamF, or spa PCR products. These genes were cloned into the broad host plasmid vector pBBR1MCS-2 (5144 bp), resulting in plasmids pBBR-mamC-spa and pBBR-mamF-spa, which were then introduced into MSR1 by conjugation. The recombinant strains harboring plasmid pBBR-mamC-spa and pBBR-mamF-spa were termed MSR-CA and MSR-FA, respectively.

To increase the amount of SPA on the recombinant magnetosomes (BMP-As), a mamF mutant strain of M. gryphiswaldense was constructed by allelic gene replacement. The native mamF 
gene in the MSR-1 genome was replaced by a gentamicin resistance gene (aminoglycoside acetyltransferase gene; aac), resulting in strain $\Delta \mathrm{F}$. The mutant strain harboring plasmid pBBR-mamF-spa was termed $\triangle$ F-FA. Recombinant magnetosomes from strains MSR-1, MSR-CA, MSR-FA, and $\triangle \mathrm{F}-\mathrm{FA}$ were termed BMP-WT, BMP-CA, BMP-FA, and $\triangle \mathrm{F}-\mathrm{BMP}-\mathrm{FA}$, respectively.

The expression of SPA on magnetosomes was confirmed by western blotting. The membrane proteins of purified magnetosomes were separated by SDS-PAGE and transferred onto a nitrocellulose membrane by electroblotting. The protein bands were colored by sequential treatment with primary $\mathrm{Ab}$, secondary Ab, and BCIP-NBT. SPA was found in all the recombinant magnetosomes (Figure 2).

\section{CHARACTERIZATION OF RECOMBINANT MAGNETOSOMES}

Strains as above were collected by centrifugation after 3 days of culture, and their magnetosomes were isolated and purified. Transmission electronic microscopy (Figure 3) showed generally similar morphology of WT magnetosomes (diameter range 35$84 \mathrm{~nm}$ ) and recombinant magnetosomes. The magnetosomes of $\Delta$ F-FA were slightly smaller $(24-48 \mathrm{~nm})$ than those of the other strains.

The hydrated radii and zeta potentials of magnetosomes were analyzed by a Zeta Potential Analyzer. All zeta potentials were lower than $-30 \mathrm{mV}$, indicating that the aqueous colloids were moderately stable. The expression of foreign proteins can affect the amount of electrical charge on interfaces between magnetosomes and aqueous solutions. The large hydrated radii of BMP-WTs indicated that several BMP-WT gathered into a larger

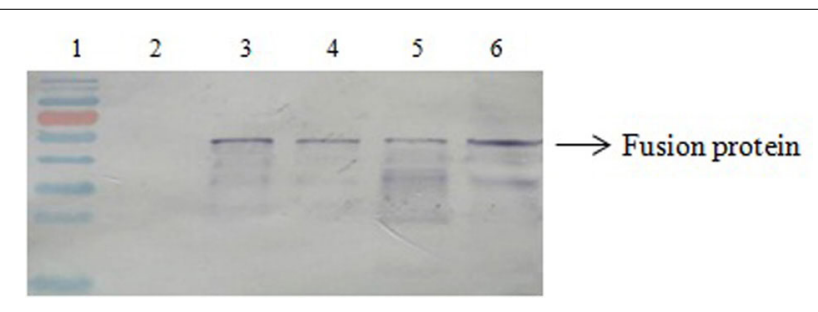

FIGURE 2 | Western blotting results. Lane 1, molecular markers; Lane 2, BMP-WT; Lane 3, BMP-CA; Lane4, fusion protein; Lane 5, BMP-FA; Lane 6, $\triangle$ F-BMP-FA. particle in suspension. The expression of foreign proteins on magnetosomes in the case of BMP-CA and BMP-FA was associated with smaller values of hydrated radii and polydispersity, indicating improved dispersity and uniformity. $\triangle \mathrm{F}$-BMP-FA had the smallest hydrated radii and best dispersity because they had the largest amount of foreign proteins.

\section{EFFICIENCY OF MAGNETOSOME LINKAGE TO POLYCLONAL Ab}

Polyclonal Abs were linked with SPA on the surface of magnetosomes by self-assembly to form functional magnetic carriers (BMP-Ab) for capturing Vibrio. In an attempt to improve linkage rate, various values of $\mathrm{pH}(6.0,7.2,7.9)$, incubation time $(30,60$, $90,120 \mathrm{~min})$, and ratio of $\mathrm{Ab}$ to magnetosomes $(250 \mu \mathrm{g}, 500 \mu \mathrm{g}$, $1.0 \mathrm{mg}$, and $1.5 \mathrm{mg} \mathrm{Ab}$ per mg magnetosomes) were used for the linkage of BMP-CA to Ab (Figure 4). The maximal linkage rate was achieved with $\mathrm{pH} 7.2$, incubation time $120 \mathrm{~min}$, and ratio 1:1.

Linkage rates of different magnetosome-Ab linking methods were compared under these optimal conditions (Figure 5). BMPWTs were linked to $\mathrm{Ab}$ by nonspecific adsorption or $\mathrm{BS}^{3}$, and BMP-CA and $\triangle$ F-BMP-FA were linked to Ab by self-assembly.

The percentage of $\mathrm{Ab}$ linked to BMP-WT by nonspecific adsorption was almost $20 \%$ and could not be ignored. However, the percentages of $\mathrm{Ab}$ coupled to magnetosomes by covalent linkage or self-assembly were significantly higher. The linkage rate of $\triangle \mathrm{F}-\mathrm{BMP}-\mathrm{FA}$ magnetosomes to $\mathrm{Ab}$ was much higher than that of other magnetosomes, indicating that $\triangle \mathrm{F}$-BMP-FA is the best candidate for magnetic carrier carriers for IMS (Table 3).

\section{IMMUNOMAGNETIC SEPARATION OF V. PARAHAEMOLYTICUS}

Anti-Vibrio rabbit polyclonal $\mathrm{Ab}$ was linked to recombinant magnetosomes (BMP-CA, BMP-FA, and $\triangle$ F-BMP-FA) by selfassembly. WT magnetosomes (BMP-WT) were linked to Ab by $\mathrm{BS}^{3}$. Magnetosome-Ab complexes (BMP-A-Ab) were used to capture $V$. parahaemolyticus. FQ-PCR was performed with the species-specific gene th as template. A standard curve was constructed by plotting the threshold cycle $(\mathrm{Ct})$ value against the log of Vibrio DNA weight (ng) by linear regression. The number of Vibrio cells was estimated based on the amount of DNA attached to the magnetosomes (Table 4).

Each type of magnetosome $(1 \mathrm{mg})$ was mixed with $1 \mathrm{~mL}$ of diluted $V$. parahaemolyticus suspension $\left(10^{-4}\right.$; approximately $2 \times$ $\left.10^{8} \mathrm{cfu}\right)$. WT magnetosomes bound a much lower number of Vibrio than did the other magnetosomes, indicating that many $\mathrm{Ab}$
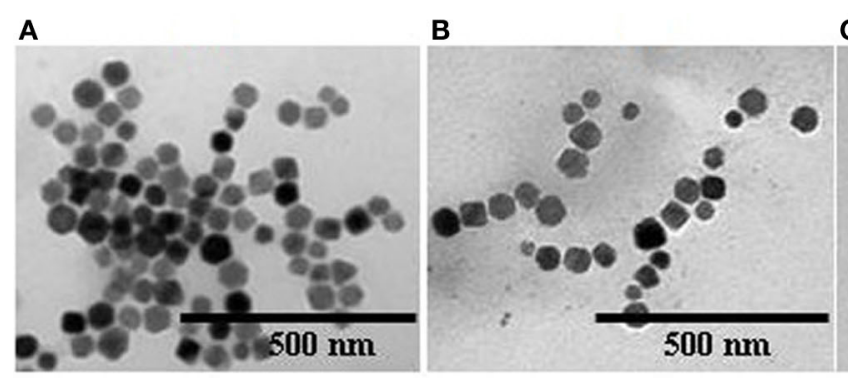

C

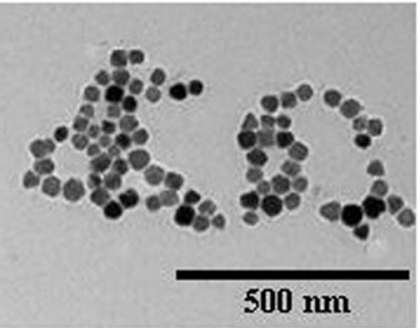

FIGURE 3 | Electron micrographs of magnetosomes from various strains. (A), BMP-WT; (B), BMP-FA; (C), $\triangle F-B M P-F A$. 

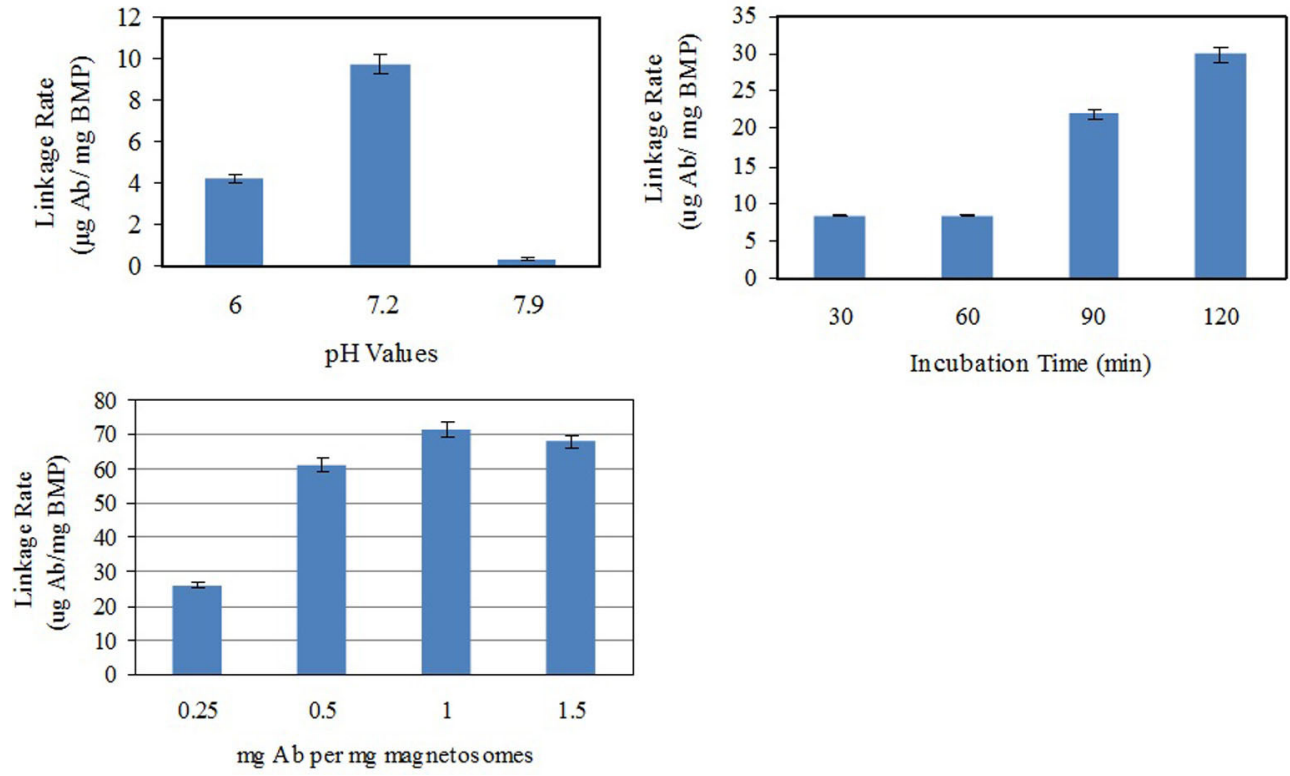

FIGURE 4 | Optimization of conditions for linkage of BMP-CA to Ab.

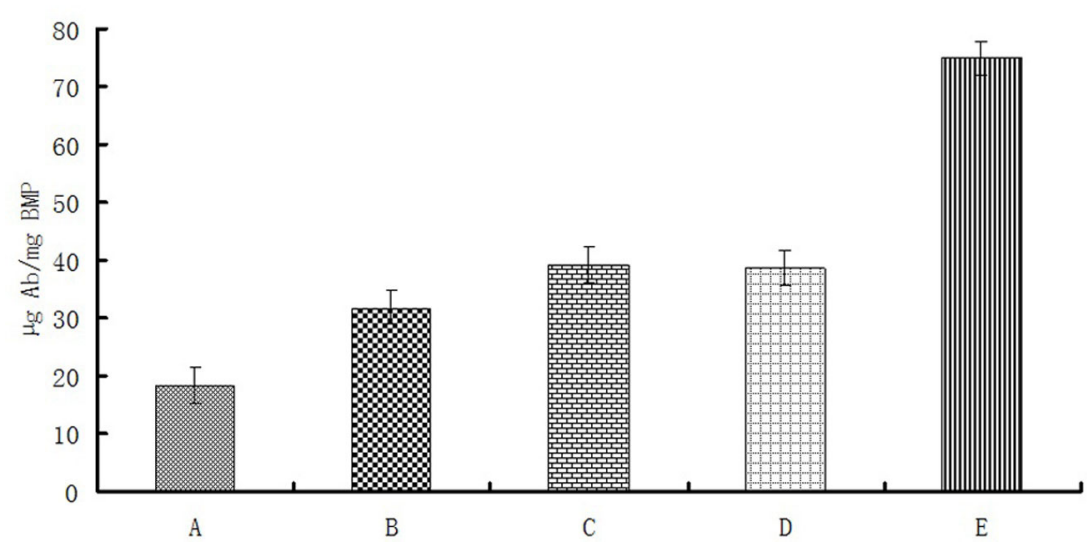

FIGURE 5 | Magnetosome-Ab linkage rates for different linkage methods under optimal conditions as in Figure 4. (A), Nonspecific adsorption of BMP-WT on $A b ;(B), B S^{3}$ linkage of BMP-WT to $A b ;(C)$, self-assembly of BMP-CA and Ab; (D), self-assembly of BMP-FA and Ab; (E) self-assembly of $\triangle F-B M P-F A$ and Ab.

Table 3 | Particle size and zeta potential of magnetosomes from various strains.

\begin{tabular}{lcccc}
\hline Strain & BMP-WT & BMP-CA & BMP-FA & \multicolumn{1}{c}{ F-BMP-FA } \\
\hline Hydrated radius $(\mathrm{nm})$ & $494.7 \pm 18.6$ & $325.2 \pm 4.2$ & $334.3 \pm 5.1$ & $152.5 \pm 0.2$ \\
Zeta potential $(\mathrm{mV})$ & $-38.27 \pm 0.73$ & $-34.09 \pm 0.5$ & $-35.12 \pm 0.6$ & $-31.09 \pm 0.79$ \\
Polydispersity & 0.354 & 0.335 & 0.337 & 0.230
\end{tabular}

molecules failed to work. $\triangle \mathrm{F}$-BMP-FA captured the highest number of Vibrio, indicating that $\triangle \mathrm{F}$-BMP-FA is the best candidate for a magnetic carrier of IMS for detection of pathogenic Vibrio.

\section{DISCUSSION}

Although MTB are ubiquitous and highly abundant in many aquatic habitats, they are very difficult to culture in laboratory or industrial situations. To date, fewer than 20 MTB strains have been successfully isolated and cultured in laboratories worldwide (Greene and Komeili, 2012). M. gryphiswaldense MSR1, the type strain of the genus Magnetospirillum, is the only MTB strain that has been cultured on a relatively larger scale (in a 1.5-ton fermenter) (Zhang et al., 2011). Mass production of magnetosomes facilitates its detailed biotechnological and 
Table 4 | Amount of DNA in Vibrio captured by magnetosome-Ab complexes.

\begin{tabular}{lcccc}
\hline Magnetosome & BMP-WT & BMP-CA & BMP-FA & DF-BMP-FA \\
\hline Amount of DNA $(\mathrm{ng})$ & 6.092 & 76.202 & 70.226 & 95.581 \\
Number of Vibrio $\left(\times 10^{8}\right)$ & 0.117 & 1.47 & 1.35 & 1.84 \\
\hline
\end{tabular}

nanotechnological studies. These bacterial magnetic nanoparticles are distinguished by unique properties such as ferrimagnetism, nanoscale size, monocrystalline structure, narrow size distribution, uniform morphology, and membrane-bound structure, and thus have been developed and investigated for various potential applications, including immunoassays, magnetofection, therapeutic drug delivery, and enzyme immobilization (Yoshino et al., 2010).

The term "surface display systems" in microbiology refers to a group of powerful techniques that utilize naturally-occurring microbial functional components to express heterologous proteins or peptides. Since the description of the first phage-display system in the mid-1980s, a variety of new systems have been reported for yeast, Gram-positive bacteria, Gram-negative bacteria, bacterial endospores, ribosomes, and mRNAs (Ullman et al., 2011). A recently developed display system based on magnetosomes (BMPs) provides superior performance for immunomagnetic separation, which facilitates high-throughput screening (HTS) (Yoshino et al., 2010). However, only a few studies have investigated or compared the effects of different fusion strategies for MM proteins (Li et al., 2010; Pollithy et al., 2011).

We have recently detected over 200 proteins on magnetosome surfaces (unpubl. data). Some of these proteins are unique to the magnetosome. MamC and MamF, the most abundant proteins on MSR-1 magnetosomes, are small proteins composed respectively of 125 amino acids (12.4 kDa) and 111 amino acids (12.3 kDa). We constructed fusion proteins by fusing mamC and $\mathrm{mamF}$ with the SPA $(43 \mathrm{kDa})$ gene, spa. The recombinant magnetosomes were capable of self-assembly with various mammalian Abs without loss of $\mathrm{Ab}$ activity. We have evaluated and compared several magnetosome surface display strategies. The highest linkage rate of Abs and recombinant magnetosomes was obtained when the genomic MM genes for constructing fusion proteins were eliminated in recipient strains. It can be explained that there were more functional fusion proteins on the recombinant magnetosomes in the mutant recipient strain than in the wild type MSR-1. The strategy of genetic manipulation developed here would also be applied to the other magnetotactic bacterial pure cultures, such as M. magneticum AMB-1 and Magnetococcus marinus MC1. Compared to the chemically produced magnetic beads, it was much more convenient for preparing recombinant magnetosome and antibody complexes because of omitting the coating and linkage procedures. Moreover, the capture efficiency of pathogens and the dispersibility in water were obviously improved comparing with magnetosome-antibody complexes connected with crosslinker (Li et al., 2010). Thus the technique in this study is also suitable for the detection and diagnosis of other pathogens, and makes it simpler, faster, and cheaper.
Our findings are consistent with a previous report that mamF deletion in MSR-1 resulted in slightly smaller magnetosome size (Scheffel et al., 2008). Although our fusion proteins contained a fragment corresponding to MamF, the recombinant magnetosomes were smaller than WT magnetosomes. At this stage, we are unclear whether functional MamF is present in the recombinant M. gryphiswaldense strain $\triangle \mathrm{F}-\mathrm{FA}$ (which harbors pBBR-mamFspa), which needs further investigations.

Interestingly, we have detected the proteins MamC and MamF (generally thought to bind to $\mathrm{MM}$ ) in cytosol and on membranes following fusion with SPA (data not shown). These findings suggest that the binding ability of MM proteins can be affected by fusion with larger soluble proteins, resulting in less SPAs on the surface of recombinant magnetosomes.

Further studies for design of functionalized magnetosomes using the system described here are in progress. Binding abilities of other MM proteins should be investigated in detail. Smaller recombinant proteins containing SPA Ig-binding domains or larger MM binding proteins could also be constructed for more efficient magnetosome display system. The magnetosme surface play technique will include but not limited to improving the separation, detection, and diagnostic analyses, or displaying SPA protein. Other functional moieties, such as enzymes, receptors, peptide hormones, growth factors, autobiotinylation signals, and protein tags for "click chemistry" could be expressed on the magnetosome particles by using our display strategies. These would endow the recombinant magnetosomes with serious functions, or even benefit the formation and reconstruction of magnetic nanostructures, such as magnetic nanotubes and nanowires in vitro.

\section{ACKNOWLEDGMENTS}

This study was supported by the National Natural Science Foundation of China (Grant No. 31270093). The authors thank Dr. S. Anderson for English editing of the manuscript.

\section{REFERENCES}

Ångela, N. M., Fabricio, R. C., Rita, de C. S., Roberta, J. R., Jose, B. C., Odir, A. D., et al. (2008). Detection of Salmonella typhimurium in raw meats using inhouse prepared monoclonal antibody coated magnetic beads and PCR assay of the fimA gene. J. Immunoassay Immunochem. 29, 58-69. doi: 10.1080/15321810 701735096

Arakaki, A., Nakazawa, H., Nemoto, M., Mori, T., and Matsunaga, T. (2008). Formation of magnetite by bacteria and its application. J. R. Soc. Interface 5, 977-999. doi: 10.1098/rsif.2008.0170

Faivre, D., and Schüler, D. (2008). Magnetotactic bacteria and magnetosomes. Chem. Rev. 108, 4875-4898. doi: 10.1021/cr078258w

Greene, S. E., and Komeili, A. (2012). Biogenesis and subcellular organization of the magnetosome organelles of magnetotactic bacteria. Curr. Opin. Cell Biol. 24, 1-6. doi: 10.1016/j.ceb.2012.05.008

Grünberg, K., Müller E. C., Otto, A., Reszka, R., Linder, D., Kube, M., et al. (2004). Biochemical and proteomic analysis of the magnetosome membrane in Magnetospirillum gryphiswaldense. Appl. Environ. Microbiol. 70, 1040-1050. doi: 10.1128/AEM.70.2.1040-1050.2004

Kaysner, C. A. and DePaola, A. Jr. (2004). Bacteriological Analytical Manual, Chapter 9Vibrio. Available online: http://www.fda.gov/Food/ FoodScienceResearch/LaboratoryMethods/ucm070830.htm

Komeili, A., Vali, H., Beveridge, T. J., and Newman, D. K. (2004). Magnetosome vesicles are present before magnetite formation, and $\mathrm{MamA}$ is required for their activation. Proc. Natl. Acad. Sci. U.S.A. 101, 3839-3844. doi: 10.1073/pnas.0400391101 
Kovach, M. E., Elzer, P. H., Hill, D. S., Robertson, G. T., Farris, M. A., Roop, R. M., et al. (1995). Four new derivatives of the broad-host-range cloning vector pBBR1MCS, carrying different antibiotic-resistance cassettes. Gene 166, 175-176. doi: 10.1016/0378-1119(95)00584-1

Li, A., Zhang, H., Zhang, X., Wang, Q., Tian, J., Li, Y., et al. (2010). Rapid separation and immunoassay for low levels of Salmonella in foods using magnetosomeantibody complex and real-time fluorescence quantitative PCR. J. Sep. Sci. 33, 3437-3443. doi: 10.1002/jssc.201000441

Liu, J., Ding, Y., Jiang, W., Tian, J., Li, Y., and Li, J. (2008). A mutation upstream of an ATPase gene significantly increases magnetosome production in Magnetospirillum gryphiswaldense. Appl. Microbiol. Biotechnol. 81, 551-558. doi: 10.1007/s00253-008-1665-1

Makino, K., Oshima, K., Kurokawa, K., Yokoyama, K., Uda, T., Tagomori, K., et al. (2003). Genome sequence of Vibrio parahaemolyticus: a pathogenic mechanism distinct from that of $\mathrm{V}$ cholerae. Lancet 361, 743-749. doi: 10.1016/S01406736(03)12659-1

McCarthy, S. A., DePaola, A., Cook, D. W., Kaysner, C. A., and Hill, W. E. (1999). Evaluation of alkaline phosphatase- and digoxigenin-labelled probes for detection of the thermolabile hemolysin ( $t$ lh) gene of Vibrio parahaemolyticus. Lett. Appl. Microbiol. 28, 66-70. doi: 10.1046/j.1365-2672.1999. 00467.x

Mercanoglu, T. B., Ben, U., and Aytac, S. A. (2009). Rapid detection of Salmonella in milk by combined immunomagnetic separation-polymerase chain reaction assay. J. Dairy Sci. 92, 2382-2388. doi: 10.3168/jds.2008-1537

Newton, A., Kendall, M., Vugia, D. J., Henao, O. L., and Mahon, B. E. (2012). Increasing rates of vibriosis in the United States, 1996-2010: review of surveillance data from 2 systems. Clin. Infect. Dis. 54(Suppl. 5), S391-S395. doi: $10.1093 / \mathrm{cid} / \mathrm{cis} 243$

Pollithy, A., Romer, T., Lang, C., Müller, F. D., Helma, J., Leonhardt, H., et al. (2011). Magnetosome expression of functional camelid antibody fragments (nanobodies) in Magnetospirillum gryphiswaldense. Appl. Environ. Microbiol. 77, 6165-6171. doi: 10.1128/AEM.05282-11

Powell, H. A., Gooding, C. M., Garrett, S. D., Lund, B. M., and McKee, R. A. (1994). Proteinase inhibition of the detection of Listeria monocytogenes in milk using the polymerase chain reaction. Lett. Appl. Microbiol. 18, 59-61. doi: 10.1111/j.1472765X.1994.tb00802.x

Rossen, L., Nørskov, P., Holmstrøm, K., and Rasmussen, O. F. (1992). Inhibition of PCR by components of food samples, microbial diagnostic assays and DNA-extraction solution. Int. J. Food Microbiol. 17, 37-45. doi: 10.1016/01681605(92)90017-W

Sambrook, J., and Russel, D. W. (2001). Molecular Cloning: a Laboratory Manual, 3rd Edn. Cold Spring Harbor, NY: Cold Spring Harbor Laboratory Press.

Scheffel, A., Gärdes, A., Grünberg, K., Wanner, G., and Schüler, D. (2008). The major magnetosome proteins MamGFDC are not essential for magnetite biomineralization in Magnetospirillum gryphiswaldense but regulate the size of magnetosome crystals. J. Bacteriol. 190, 377-386. doi: 10.1128/JB. 01371-07
Schüler, D. (2002). The biomineralization of magnetosomes in Magnetispirillum gryphiswaldense. Int. Microbiol. 5, 209-214. doi: 10.1007/s10123-0020086-8

Sidorin, E. V., and Solov'eva, T. F. (2011). IgG-binding proteins of bacteria. Biochemistry (Mosc.) 76, 295-308. doi: 10.1134/S0006297911030023

Spanová, A., Rittich, B., Horák, D., Lenfeld, J., Prodelalová, J., Suciková, J., et al. (2003). Immunomagnetic separation and detection of Salmonella cells using newly designed carriers. J. Chromatogr. A 1009, 215-221. doi: 10.1016/S00219673(03)00431-X

Su, Y. C., and Liu, C. (2007). Vibrio parahaemolyticus: a concern of seafood safety. Food Microbiol. 24, 549-558. doi: 10.1016/j.fm.2007.01.005

Takahashi, M., Yoshino, T., and Matsunaga, T. (2010). Surface modification of magnetic nanoparticles using asparagines-serine polypeptide designed to control interactions with cell surfaces. Biomaterials 31, 4952-4957. doi: 10.1016/j.biomaterials.2010.02.048

Ullman, C. G., Frigotto, L., and Cooley, R. N. (2011). In vitro methods for peptide display and their applications. Brief. Funct. Genomics 10, 125-134. doi: 10.1093/bfgp/elr010

Waleed, A. A., and Peter, R. (2000). Effects of amplification facilitators on diagnostic PCR in the presence of blood, feces, and meat. J. Clin. Microbiol. 38, 4463-4470.

Yoshino, T., Maeda, Y., and Matsunaga, T. (2010). Bioengineering of Bacterial Magnetic Particles and their Applications in Biotechnology. Recent Pat. Biotechnol. 4, 214-225. doi: 10.2174/187220810793611455

Zhang, Y., Zhang, X., Jiang, W., Li, Y., and Li, J. (2011) Semicontinuous culture of Magnetospirillum gryphiswaldense MSR-1 cells in an autofermentor by nutrient-balanced and isosmotic feeding strategies. Appl. Environ. Microbiol. 77, 5851-5856. doi: 10.1128/AEM.05962-11

Conflict of Interest Statement: The authors declare that the research was conducted in the absence of any commercial or financial relationships that could be construed as a potential conflict of interest.

Received: 24 August 2013; accepted: 17 March 2014; published online: 03 April 2014. Citation: Xu J, Hu J, Liu L, Li L, Wang X, Zhang H, Jiang W, Tian J, Li Y and Li J (2014) Surface expression of protein A on magnetosomes and capture of pathogenic bacteria by magnetosome/antibody complexes. Front. Microbiol. 5:136. doi: 10.3389/ fmicb.2014.00136

This article was submitted to Aquatic Microbiology, a section of the journal Frontiers in Microbiology.

Copyright (c) $2014 \mathrm{Xu}, \mathrm{Hu}$, Liu, Li, Wang, Zhang, Jiang, Tian, Li and Li. This is an open-access article distributed under the terms of the Creative Commons Attribution License (CC BY). The use, distribution or reproduction in other forums is permitted, provided the original author(s) or licensor are credited and that the original publication in this journal is cited, in accordance with accepted academic practice. No use, distribution or reproduction is permitted which does not comply with these terms. 